\title{
Planetariums between experience and enlightenment
}

\author{
Marianne Achiam, Line BruUn Nicolaisen \& Tina IbSen
}

\begin{abstract}
Planetariums are committed to promoting public knowledge about astronomy and space. At the same time, they have a legacy of offering spectacular and immersive experiences in their dome programmes. These outcomes do not always sit comfortably together; in fact, international research shows that many planetarium staff members consider experience and enlightenment to be mutually exclusive. In this study, we develop the argument that enlightenment and experience do not necessarily contradict each other in the planetarium context. We survey staff members from Scandinavian planetariums on their perspectives of planetarium dome programmes, and show that here, enlightenment and experience are considered to be complementary in successful planetarium dome dissemination. We discuss these findings and offer our reflections on their implications for the practice of planetariums.
\end{abstract}

Keywords: Science education, didactics, science centres, museum professionals, learning.

Since the emergence of the first dome-shaped projection planetariums in Europe and the United States in the early twentieth century, scholars have discussed whether the essential effect of the planetarium is in the cognitive or the affective domain (Smith 1974, Sunal 1976). These discussions should be seen against different cultural backdrops: In the United States, the Sputnik Shock in 1957 resulted in a proliferation of projection planetariums as parts of a larger infrastructure to support the development of a scientifically literate public (Slater \& Tatge 2017). Many American planetariums were thus primarily associated with primary, secondary or tertiary education institutions; a focus that seemed to permeate or even trump discussions of the more immersive or aesthetic aspects of the planetarium, as illustrated in the following statement made by planetarium director Dr Charles Henry King in 1966:

Give [the public] what they want - entertainment, thrills, and means of escape from the cares and worries of the "world outside." Provide excitement, drama, and spectacle. Let them see the sun, moon, and planets career across the sky. [...] In brief, do anything that will help conceal the unpleasant truth 


\section{Marianne AChiam, Line BruUn Nicolaisen \& Tina IbSen}

that a planetarium is primarily an educational device and is, or should be, concerned with astronomy (King 1966, cited in Griffiths 2008:132).

In contrast, in the early twentieth century, European projection planetariums were acknowledged not just in the contexts of science and education, but also in the contexts of performance and aesthetics (Wolfschmidt 2007). These cultural institutions were considered to be "theatres of the stars" located at the intersection of science, technology and spectacle (Bigg \& Vanhoutte 2017). Indeed, the sensory nature of the planetarium was not seen as antithetical to education, but rather, as well-suited to contemporary object- and experience-based pedagogies (e.g. Deinhardt 1934). Sensory experience and imagination were seen as appropriate pathways to learning (Bigg 2017).

In spite of their different cultural settings, European and American planetariums also had similarities. Towards the end of the twentieth century, planetarium technology across the western hemisphere had progressed to the point where it was possible to immerse visitors in virtual space-travel: Planetariumgoers could now travel to the Moon, planet Mars, or beyond (Backhus 2013). More and more, the planetarium dome became a performative space (Griffiths 2008; Vanhoutte \& Bigg 2014) in which visitors could see the universe from places no human can go, in ways that are inaccessible to human perception (Eriksson 2014). The gradual evolution of this basic planetarium characteristic, in which technology mediates that which lies beyond human perception, and immerses visitors in what it "is like" in space (Bleeker 2017), seems to imply that in modern digital planetarium domes, there cannot be education without experience.
Even so, many present-day accounts of planetariums from both Europe and the United States seem to view the educational and the spectacular as two ends of a spectrum, or even mutually exclusive (Croft 2008). For instance, in his reflections on the prospective new planetarium in Strasbourg, Soubiran (2017) points to tensions between scientific and spectacular astronomy, between education and entertainment, and between pedagogy and wonder. Backhus (2013) discusses how, in US planetariums, the objectives of education and entertainment are described as counterparts. Finally, in a study of planetarium education professionals, Croft (2008:17) observes how they "struggle[d] to make complex scientific concepts understandable to their audiences within the aesthetic medium [of the dome programme]". Similar dichotomous perceptions are present among planetarium education professionals studied by Littmann (2009) and Plummer \& Small (2013).

To summarise, in spite of what we might describe as the fundamental immersive performativity of the modern planetarium dome in which education and aesthetic experience are inextricably linked, we observe a dichotomisation in recent history between the notion of the planetarium dome as a milieu that promotes scientific knowledge, and the notion of the dome as a milieu that offers more sensory experiences of space. From a museological perspective, this relationship seems recognisable as the more general distinction between the Enlightenment ideal of providing public education and the more consumer-oriented ideal of offering entertaining experiences (Anderson 2004, Black 2012). In the following, we thus use the terms enlightenment and experience to signify these two characteristics of planetarium dome programmes (table 1). 


\begin{tabular}{lcll}
\hline Enlightenment & vs. & Experience & Reference \\
\hline cognitive & vs. & affective & Smith (1974) \\
didactic & vs. & aesthetic & Wolfschmidt (2007) \\
scientific & vs. & aesthetic & Croft (2008) \\
science & vs. & spectacle & Griffiths (2008) \\
education & vs. & entertainment & Backhus (2013) \\
pedagogy & vs. & wonder & Soubiran (2017) \\
\hline
\end{tabular}

Table 1. Examples of dichotomous terms used by planetarium practitioners and researchers to describe tensions related to planetarium dome dissemination programmes, summarised here as "enlightenment" and "experience", respectively.

We formulate our research question in the following way: How do presentday, Scandinavian planetarium education professionals perceive the relationship between enlightenment and experience with respect to their dome programmes, and what are the implications of this perception for planetarium practice? In the following sections, we develop our methodological perspective and explain our data collection and analysis procedures.

\section{METHODOLOGY}

We approach our research question from what Anderson and Ellenbogen (2012) designate as a relativist-contextualist research paradigm. This means that rather than searching for an objective, generalisable "truth", we focus on the localised and subjective meanings of human experience (cf. Treagust, Won \& Duit 2014). We see educational environments such as planetarium dome programmes as rich and complex phenomena, and we attempt to capture planetarium professionals' perceptions of this complexity using qualitative and interpretivist methods.

Our study consisted of three main phases.
In the first phase, we collected and studied the research on planetarium dissemination, educators, and dome programmes referenced in the preceding. In our group, which consisted of two university researchers and one planetarium professional, discussions of these texts served not only to establish and validate the problem at stake, but also to make the dimensions of enlightenment and experience recognisable and meaningful from perspectives of both practice and research.

In the second phase, we constructed an online questionnaire in Google Forms (see Appendix) to gather data from planetarium education professionals in the Scandinavian countries. In addition to a set of closed-ended demographic questions, we developed a set of multiple-choice questions to uncover the connotations of the terms enlightenment and experience among respondents. Further, we developed a number of open-ended questions about respondents' specific perceptions of enlightenment and experience in relation to their individual dome programmes. In particular, the open-ended questions were an attempt to gain access to the rich verbal descriptions that characterise research in the 


\section{Marianne Achiam, Line BruUn Nicolaisen \& Tina IbSen}

relativist-contextualist paradigm (Treagust, Won \& Duit 2014).

In the third phase, we collected, analysed, and discussed responses from planetarium education professionals. In this phase, we carefully scrutinised the data to "crystallise" strong and valid images of respondents' lived experiences (Denzin \& Lincoln 2011). The specific procedures are described in detail in the following section; the third phase was concluded with the reporting of our study (the present text). In this reporting, we attempt to provide a detailed narrative of our procedures and findings (Treagust, Won \& Duit 2014).

\section{DATA COLLECTION AND ANALYSIS}

In the autumn of 2018, we distributed the online questionnaire to planetarium professionals from institutions that were members of the Nordic Planetarium Association (NPA) and located in Sweden, Denmark, and Norway. The questionnaire was distributed through several channels: The NPA newsletter, the NPA's pages on social media channels Facebook and Slack, and by direct email to all members that attended the bi-annual NPA meeting in 2017. The questionnaire was distributed to $45 \mathrm{NPA}$ members, and 13 (or 29 percent) responded.

The questionnaire had two sections. The first section inquired about respondents' own views on their planetarium programmes, whereas the second introduced the notions of experience and enlightenment. The respondents were not able to view the second section before they had responded to the first. They were thus not aware of the experience/enlightenment theme of the questionnaire when they responded to the first section, and their initial answers were presumably not prompted or guided by this theme.

\section{Multiple choice questions}

We developed the multiple-choice questions in our questionnaire to understand what connotations the two terms enlightenment and experience held for our respondents. To this end, we constructed a list of twelve phrases that reflected different aspects of dissemination, and asked respondents to indicate which of these terms they associated with enlightenment, with experience, with both, or with none. We assumed that if enlightenment and experience were perceived as mutually exclusive, the responses would show a clear bimodal distribution, whereas if enlightenment and experience were seen as being related, many of the twelve phrases would be associated with both enlightenment and experience.

We mapped the responses with the network visualisation software Gephi, using the Force Atlas layout. In this layout, "nodes" physically repulse each other, while connections between nodes attract them to one another, as if they were connected by springs (Jacomy et al. 2014). In the resulting network, the physical proximity of the twelve "phrase" nodes to the enlightenment and experience nodes thus represents the degree to which they are attracted to (i.e. associated with) enlightenment and experience, respectively.

\section{Open-ended questions}

We formulated two essential, open-ended questions to explore the planetarium professionals' perceptions of experience and enlightenment with respect to their individual dome programmes. We were interested in obtaining their own phrasing and wordings to uncover their perspectives on their dome programmes.

The first open-ended question asked respondents to describe the most important 
goal for their planetarium dome programmes. As mentioned, this question was posed before the respondents were introduced to the notions of experience and enlightenment in the questionnaire. In the second open-ended question, the planetarium professionals were asked to give an example from their dome programme that illustrates the relationship they describe between experience and enlightenment. This question was posed after the multiple-choice questions described in the preceding, where respondents were prompted to indicate their perceptions of the notions of experience and enlightenment and the relationships between the two notions. We analysed the data resulting from the openended questions using the six-step thematic analysis method described by Braun and Clarke (2006).

\section{RESULTS}

Thirteen planetarium professionals responded to the questionnaire; of these, five were from Denmark, five were from Sweden, and three were from Norway. In the following, the responding professionals are designated as Respondent 1 through 13.

\section{Objectives of planetarium dome programmes}

When describing the primary goals of their planetarium dome programmes, planetarium professionals overwhelmingly used terms reflecting affective or aesthetic processes, as illustrated by the following responses:

Respondent 2: Stimulating the curiosity and sense of wonder

Respondent 8: To provide an experience that piques the visitor's curiosity

Respondent 9: To give the visitors a taste of space
Some respondents used terms that had educational or scientific aspects; however, these terms were always juxtaposed with terms associated with affective or aesthetic processes:

Respondent 1: Education, inspiration, encouragement to seek higher education

Respondent 5: A nice experience where a bit of science and/or natural history is included

Respondent 12: Edutainment (Education and Entertainment)

These responses indicate that while the primary objective of planetarium dome programmes may be related to lived aesthetic or affective processes, such processes are not necessarily perceived to be in opposition to education or learning about science. Indeed, the planetarium professionals' responses to the multiple-choice questions (presented in the following) support this conjecture.

\section{Relationship between experience and enlightenment}

Among the responding planetarium professionals, there seemed to be a collective sense that experience and enlightenment were related to each other in a number of ways (fig. 1). Although some phrases were more strongly associated with experience (e.g. "sensing", "feeling", or "enjoying") and others were more strongly associated with enlightenment (e.g. "education", "thinking" or "understanding"), none of the phrases were exclusively associated with one term or the other. In particular, the phrase "learning" was strongly associated with both enlightenment and experience by the respondents.

Accordingly, we interpret the data visualised in figure 1 to mean that planetarium professionals do not have a dichotomous perception 


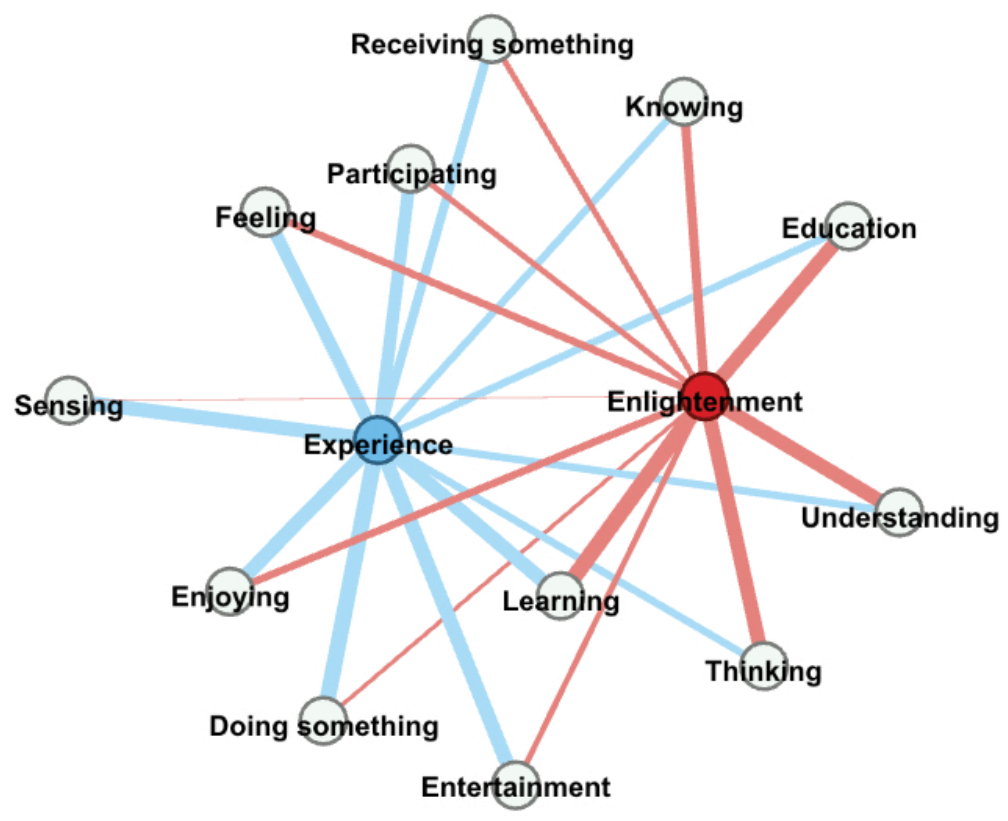

Fig. 1. Visualisation of planetarium professionals' associations of the terms experience (blue node) and enlightenment (red node) with twelve phrases related to dissemination (white nodes). The width of the connecting lines indicates the number of instances in which two nodes were connected.

of enlightenment and experience, but rather, that the two are perceived to be connected. In the following section, we present data to further support and elaborate this conjecture.

\section{Experience and enlightenment in planetarium dome programmes}

When asked specifically about the interconnectedness of enlightenment and experience in planetarium dome dissemination, all responding planetarium professionals affirmed that "Dome programmes can focus on the visitor's enlightenment and their experience at the same time. A programme that is enlightening is also experiential, and vice versa". Finally, when asked to exemplify this association with a point of departure in their own dome programmes, a correlation between the notions emerged, as illustrated in the following:

Respondent 3: The guest has a sensory experience with the vastness of space, and I hope this gives them an enlightened feeling of the same.

Respondent 7: When using the digital universe system, travelling around between planets is an overwhelming experience. When we at the same time teach the audience about the planets, you get enlightenment and experience at the same time.

Respondent 11: The aim [of our dome show] 
is to involve, intrigue and inspire the audience and in the process potentially allow them to access previously unknown concepts and ideas.

Our interpretation of the planetarium professionals' responses is that they consider the relationship between enlightenment and experience to be complementary or even causal, in other words that experience is seen by planetarium professionals as the means to reach the ultimate end of enlightenment. We shall return to this interpretation in the discussion.

\section{Summary of results}

The planetarium professionals' responses to the questionnaire seemed to follow parallel trajectories wherein the majority initially associated their dome programmes with aesthetic experience, while some additionally associated the programmes with more scientific, knowledge-acquisition outcomes. When prompted, all respondents observed that enlightenment and experience can and do co-exist in planetarium dome programmes. Finally, in their reflections about how the two co-exist in their own dome programmes, the planetarium professionals indicate a correlation or even causality between them: experience can lead to enlightenment.

\section{Discussion}

In the present study, we set out to understand the ways in which Scandinavian planetarium education professionals perceive the relationship between enlightenment and experience with respect to their dome programmes, and to explore the implications of these perceptions for planetarium practice. Our primary result - that experience and enlightenment are perceived as complementary relationship - contrasts with the perceptions of (non-Scandinavian) planetarium professionals published in the literature; yet, as we discussed in the introduction, is perhaps not surprising given the immersive performativity of the planetarium dome. In the following, we briefly discuss some limitations of this study. We then proceed to considering possible reasons for the divergence of perception between planetarium professionals in international studies and in the Scandinavian case. We finally offer our thoughts on the implications of our findings for planetarium practice.

\section{Limitations of this study}

Our empirical material consists of responses from just 13 planetarium professionals, with considerable variation in length. Ideally, these written responses would have been explored through, for instance, qualitative interviews (cf. Treagust, Won \& Duit 2014); however, this was beyond the scope of the work carried out here. The evident limitations of our dataset are further compounded by the fact that we, in our initial search for literature on planetarium professionals and dome programmes, were not able to locate any studies carried out in Scandinavian or Nordic contexts. Taken together, this means that we have difficulty assessing how much our findings can be generalised across the Scandinavian context.

The lack of Scandinavian or Nordic planetarium studies also means that we don't have a strong sense of the extent to which our findings are in fact an indicator that Scandinavian planetarium practice differs from that of other planetariums. In the following, we provide possible explanations for our findings, but we cannot rule out that the particular construction of our questionnaire 


\section{Marianne AChiam, Line BruUn Nicolaisen \& Tina IbSen}

was what prompted responses that differed from those published in the literature. Thus, one explanation for the divergence between international and Scandinavian planetarium professionals with respect to enlightenment and experience is that our methodology prompted the differences. We attempted to avoid this issue by asking openended questions with free-text answers, thus allowing respondents to phrase their own understandings, but we cannot be sure that we didn't inadvertently cause the divergence. However, in the following we proceed on the assumption that this was not the case.

\section{Diverging perceptions of enlightenment and experience in planetariums}

Planetarium dome programmes are what Griffiths (2008:116) calls intermedial events, in the sense that they combine spectacular display techniques with scientific performance. We have argued that this means that it is difficult or even impossible to separate their experiential aspects from their enlightenment-related ones. Why, then, do we find so many examples in the literature of planetarium professionals who struggle to reconcile those two aspects?

One possible answer to this question may be based in ideology. The traditional Enlightenment model of science is one of reason, neutral rationality, and dispassion; these characteristics have also permeated the present-day domain of public communication and engagement in science (Elam \& Bertilsson 2003). This means that many efforts to engage the public in science have tended to ignore the non-discursive aspects of science such as materiality, embodiment and affect (Davies 2014). In this light, perhaps it is no wonder that many planetarium professionals find the experiential aspects of the planetarium dome programmes difficult to reconcile with their scientific ambitions. But why do Scandinavian planetarium professionals seemingly have a different perspective?

\section{The case of Scandinavian planetariums}

Cultural institutions such as planetariums do not exist in a vacuum, but are part of the societies that surround them (Kreps 2006). This means that their practices are shaped not only by their specific institutional cultures, but also by the socio-cultural systems they exist within (Achiam \& Marandino 2014). When we consider the perceptions of education professionals in Scandinavian planetariums, we should therefore consider not only what it means to be a planetarium, but also what it means to be Scandinavian. In this context, the Nordic model of education offers one possible explanation for the particular perceptions of Scandinavian planetarium professionals, and their divergence from those of other planetarium professionals.

The Nordic model of education, founded in the years following the Second World War, focuses on promoting not just scientific knowledge but also personal growth (Telhaug, Mediås \& Aasen 2006). Especially in the Scandinavian subsets of this model, the emphasis is equally on cognitive, affective, and skills development, and learning is perceived to involve experience that is acted and reflected on by the learner (Kanuka 2015). If we zoom in on the case of science education, we again find a shared Scandinavian perspective that echoes these characteristics, emphasising the role of the cultural, aesthetic and affective aspects of science for education (Andersen et al. 2004).

Accordingly, we suggest that one way to explain our results is in terms of this shared Scandinavian perception of (science) education as involving not only cognitive components, but also aesthetic and affective components; 
in other words, both enlightenment and experience. Even though planetariums and their dome programmes share their genealogy with similar institutions around the world, the specific cultural setting of the Scandinavian planetariums studied here thus seems to entail an encoding of the planetarium dome programmes in terms of the particular Scandinavian ways of seeing, valuing, ascribing meaning to and treating scientific practices (cf. Achiam \& Marandino 2019).

Of course, the explanation we offer here is speculative, and warrants further examination. An alternative hypothesis might reasonably situate Scandinavian planetariums within the larger European planetarium community, and thus explain the divergence in terms of the different historical contexts for American and European planetariums (as briefly outlined in the introduction). Due to the patchy and heterogenous nature of research on planetariums before 1990 (Slater \& Tatge 2017), this hypothesis would require a careful and in-depth historical synthesis of findings from both sides of the North Atlantic. We hope to able to provide such a synthesis in the future.

\section{Implications for planetarium practice}

For planetariums, an acknowledgement of the complementary (or even causal) relationship between experience and enlightenment may have particular significance. We have already discussed how the Enlightenment ideal tends to disregard aspects of science such as materiality, embodiment and affect. This phenomenon may be even more pronounced with respect to the planetarium disciplines astrophysics, cosmology and space technology, which are framed as rational, abstract, objective, difficult and elitist (Due 2014). As a result, they tend to attract and include only those individuals whose identities fit comfortably with such characteristics (Danielsson 2012; Leslie et al 2015). What this means is that if and when planetariums more fully and explicitly embrace the experiential, aesthetic and embodied aspects of astrophysics, cosmology and space technology as well as the abstract and rational aspects, those planetariums are offering their visitors a more nuanced representation of these disciplines, as well as a more welcoming and inclusive one (cf. Bracey 2017).

Another important implication of embracing both the enlightenment and the experience aspects of the planetarium disciplines is related to the larger cultural and societal discussion of the benefit to humanity of space technology and exploration. Griffin (2014) discusses how space agencies such as ESA and NASA employ a positivist discourse in their outreach activities that positions these benefits as universal and self-evident, disregarding or even diminishing members of the public who do not comprehend or agree with them. Here, Griffin argues, there is a role for the 'affective space' that is produced along with space technology and spacefaring, because large parts of these disciplines can only be accessed through their imaginaries (Griffin 2014). In other words, planetariums are well positioned to contribute to a deeper public discussion of the benefits of exploring and understanding space by engaging their visitors in more holistic experiences of these disciplines.

\section{FINAL WORDS}

We would argue that planetarium professionals worldwide could benefit from embracing the spectacular, embodied, indeed experiential aspects of the dome programme in their considerations of its enlightenment potential. As Bigg \& Vanhoutte (2017:116) observe, "the spectacularisation of the 'hard' 


\section{Marianne AChiam, Line BruUn Nicolaisen \& Tina IbSen}

sciences has been under-theorised", yet this spectacularisation could have an important role to play in creating a scientifically literate citizenship. Institutions such as planetariums have the unique potential to offer the public symbolic experiences that transcend time and place (Achiam 2016); such experiences, we would argue, are as much a part of science as the dispassionate reasoning of the Enlightenment ideal. Although the present study has probably raised more questions than it has answered, we hope that it will spark new discussions about planetariums and their larger educational and cultural role in contemporary society.

\section{LITERATURE}

Achiam, Marianne 2016. "The role of the imagination in museum visits." Nordisk Museologi 16:1, 89100. DOI: https://doi.org/10.5617/nm.3066

Achiam, Marianne \& Martha Marandino 2014. "A framework for understanding the conditions of science representation and dissemination in museums." Museum Management and Curatorship 29:1, 66-82. DOI: 10.1080/09647775.2013.869855.

Achiam, Marianne \& Martha Marandino 2019. "Intended and realised educational messages of dioramas. An international comparison." In Annette Seerschoi \& Sue Dale Tunnicliffe (eds.). Natural history dioramas: Traditional exhibits for current educational themes. Socio-cultural aspects. Cham: Springer, 131-145. DOI: https://doi. org/10.1007/978-3-030-00208-4_9

Andersen, Annemarie Møller, Søren Breiting, Henrik Busch, Trine Hyllested, Kirsten Nielsen, Jan Sølberg, Helene Sørensen \& Lars Domino Østergaard 2004. "Naturfagsdidaktik som områdedidaktik." In Karsten Schnack (ed.). Didaktik på kryds og tvoers. København: Danmarks Pædagogiske Universitets Forlag, 121-163.

Anderson, David \& Kirsten M Ellenbogen 2012. "Learning science in informal contexts.
Epistemological perspectives and paradigms." In Barry J. Fraser, Kenneth Tobin \& Campbell J. McRobbie (eds.). Second International Handbook of Science Education. Springer Netherlands, 1179-1187. DOI: https://doi.org/10.1007/978-14020-9041-7_78

Anderson, Gail (ed.) 2004. Reinventing the Museum: Historical and Contemporary Perspectives on the Paradigm Shift. California: AltaMira Press.

Backhus, DeWayne A. 2013. "Peterson Planetarium. Six decades of informal science education delivery and outreach at Emporia State University." Emporia State Research Studies 49:1, 7-14. Bigg, Charlotte 2017. "The view from here, there and nowhere? Situating the observer in the planetarium and in the solar system." Early Popular Visual Culture 15:2, 204-226. DOI: 10.1080/17460654.2017.1323409.

Bigg, Charlotte \& Kurt Vanhoutte 2017. "Spectacular astronomy." Early Popular Visual Culture 15:2, 115-124. DOI: 10.1080/17460654.2017.1319037.

Black, Graham 2012. Transforming museums in the twenty-first century. London: Routledge.

Bleeker, Maaike 2017. "Who knows? The universe as technospace." Early Popular Visual Culture 15:2, 247-257. DOI: 10.1080/17460654.2017.1319083.

Bracey, Zoë E. Buck 2017. "Students from nondominant linguistic backgrounds making sense of cosmology visualizations." Journal of Research in Science Teaching 54:1, 29-57. DOI:10.1002/ tea.21337.

Braun, Virginia \& Victoria Clarke 2006. "Using thematic analysis in psychology." Qualitative Research in Psychology 3:2, 77-101. DOI: 10.1191/1478088706qp063oa.

Croft, James 2008. "Beneath the dome: GoodWork in planetariums." In Howard Gardner (ed.). GoodWork ${ }^{\oplus}$ Project Report Series, number 58.

Danielsson, Anna T. 2011. "Exploring woman university physics 'doing gender' and 'doing physics." Gender and Education 24:1, 25-39. DOI: 10.1080/09540253.2011.565040. 
Davies, Sarah R. 2014. "Knowing and loving. Public engagement beyond discourse." Science \& Technology Studies 28:3, 90-110.

Deinhardt, Otto 1934. "Das Zeiss Planetarium im Dienste der Himmelskunde für Volksschulen" [The Zeiss Planetarium and its Use for Astronomy in the People's Schools]. Leipzig: Volkmar.

Denzin, Norman K. \& Yvonna S. Lincoln 2011. "Introduction. The discipline and practice of qualitative research." In N. K. Denzin and Y. S. Lincoln (eds.). SAGE Handbook of Qualitative Research, 4th. Thousand Oaks: Sage, 1-19. DOI: https://doi.org/10.1108/09504120610655394

Due, Karin 2014. "Who is the competent physics student? A study of students' positions and social interaction in small-group discussions." Cultural Studies of Science Education 9:2, 441-459. DOI: 10.1007/s11422-012-9441-z.

Elam, Mark \& Margareta Bertilsson 2003. "Consuming, engaging and confronting science. The emerging dimensions of scientific citizenship." European Journal of Social Theory 6:2, 233-251. DOI: 10.1177/1368431003006002005.

Eriksson, Urban 2014. Reading the sky. From starspots to spotting stars. Digital Comprehensive Summaries of Uppsala Dissertations from the Faculty of Science and Technology 1196. Uppsala: Acta Universitatis Upsaliensis.

Griffin, Joanna Mary 2014. "Experience and viewpoints in the social domain of space technology." PhD monograph, Faculty of Arts and Humanities, University of Plymouth.

Griffiths, Alison 2008. "A moving picture of the heavens. Immersion in the planetarium space show." In Alison Griffiths (ed.). Shivers down your spine: Cinema, museums, and the immersive view. New York: Columbia University Press, 114-156. DOI: https://doi.org/10.1215/9780822394167-011 Jacomy, Mathieu, Tommaso Venturini, Sebastien Heymann \& Mathieu Bastian 2014. "ForceAtlas2, a continuous graph layout algorithm for handy network visualization designed for the Gephi software." PLOS ONE 9:6. DOI: 10.1371/journal. pone.0098679.

Kanuka, Heather 2015. "Philosophical orientations of teaching and technology. A Scandinavian case study." In Trine Fossland, Helle Mathiasen \& Mariann Solberg (eds.). Academic Bildung in net-based higher education, edited by. Oxon: Routledge, 73-89.

Kreps, Christina 2006. "Non-Western models of museums and curation in crosscultural perspective." In Sharon Macdonald (ed.). A companion to museum studies. Malden: Blackwell Publishing, 457-472. DOI: https://doi. org/10.1002/9780470996836.ch28

Leslie, Sarah-Jane, Andrei Cimpian, Meredith Meyer \& Edward Freeland 2015. "Expectations of brilliance underlie gender distributions across academic disciplines." Science 347:6219, 262. DOI: https://doi.org/10.1126/science.1261375

Littmann, Mark 2009. Voices from educational planetariums. Sky \& Telescope October. Accessed 07/08/18.

Plummer, Julia D. \& Kim J. Small 2013. “Informal science educators' pedagogical choices and goals for learners. The case of planetarium professionals." Astronomy Education Review 12:1, 1-16. DOI: 10.3847/AER2013004.

Slater, Timothy F., \& Coty B. Tatge 2017. Research on teaching astronomy in the planetarium. Cham: Springer.

Smith, Theodore V. 1974. The planetarium in education. A review of the literature. Davie: Nova University.

Soubiran, Sébastien 2017. "A trip to heaven. Building a new planetarium at the university of Strasbourg." Early Popular Visual Culture 15:2, 258-267. DOI: 10.1080/17460654.2017.1318519.

Sunal, Dennis W. 1976. "Analysis of research on the educational uses of a planetarium." Journal of Research in Science Teaching 13:4, 345-349.

Telhaug, Alfred O., Odd A. Mediås \& Petter Aasen 2006. “The Nordic Model in education. Education 


\section{Marianne AChiam, Line BruUn Nicolaisen \& Tina IbSEN}

as part of the political system in the last 50 years." Scandinavian Journal of Educational Research 50:3, 245-283.

DOI: $10.1080 / 00313830600743274$.

Treagust, David F, Mihye Won \& Reinders Duit 2014. "Paradigms in science education research." In N. G. Lederman and S. C. Abell (eds.). Handbook of Research on Science Education. New York: Routledge, 3-17. DOI: https://doi. org/10.4324/9780203097267.ch1

Vanhoutte, Kurt \& Charlotte Bigg 2014. “On the border between performance, science and the digital. The embodied orrery." International Journal of Performance Arts and Digital Media 10:2, 255-260.

DOI: $10.1080 / 14794713.2014 .946291$.

Wolfschmidt, Gudrun 2007. "Popularization of astronomy: From models of the cosmos to stargazing." Science \& Education 16:6, 549-559. DOI: 10.1007/s11191-006-9033-y.

\section{Appendix}

The questions from the online Google Forms questionnaire distributed to planetarium education professionals.
Marianne Achiam, Associate Professor achiam@ind.ku.dk

Department of Science Education

University of Copenhagen

Øster Voldgade

DK-1350 Copenhagen K, Denmark

Line Bruun Nicolaisen, Ph.D.-fellow nicolaisen@ind.ku.dk

Department of Science Education

University of Copenhagen

Øster Voldgade

DK-1350 Copenhagen K, Denmark

Planetarium (formerly Tycho Brahe

Planetarium), Copenhagen

Gl. Kongevej 10

DK-1610 Copenhagen V, Denmark

Tina Ibsen

Planetarium (formerly Tycho Brahe Planetarium), Copenhagen

Gl. Kongevej 10

DK-1610 Copenhagen V, Denmark 


\section{Planetarium Dissemination in the Dome}

This survey is about the dissemination of astronomy, space travel and related subjects that is carried out using the planetarium dome in your planetarium. We are interested in programmes, with or without live presentations by planetarium professionals, that include the projection of images on the dome surface. For this survey, please answer based on the programmes your planetarium offers to casual visitors, i.e. not those for school groups (unless they are the same)!

\section{Section 1: About you and your planetarium}

Where is your planetarium located?

Denmark

Norway

Sweden

Thinking about yourself as a planetarium professional, is your educational background more strongly linked to science or to education?

Science (e.g. astronomy, physics, natural sciences, engineering, technology, etc.)

Education (e.g. pedagogy, psychology, education studies, teacher professional development, etc.)

Other: [Long answer textbox]

In your opinion, what is the most important goal for your planetarium's dome programmes (for casual visitors, not schools)?

[Long answer textbox]

\section{Section 2: Your general ideas about 'enlightenment' and 'experience'}

We are interested in your ideas about the terms 'enlightenment' and 'experience', and what they mean to you.

Please indicate which words you associate with the two terms. You can check two, one or no boxes in each row.

\section{Doing something}

Enlightenment Experience

2. Receiving something

3. Thinking

4. Entertainment

5. Participating

6. Learning 


$\begin{array}{lcc}\text { 7. Knowing } & \square & \square \\ \text { 8. Feeling } & \square & \square \\ \text { 9. Sensing } & \square & \square \\ \text { 10. Education } & \square & \square \\ \text { 11. Enjoying } & \square & \square \\ \text { 12. Understanding } & \square & \square\end{array}$

\section{The relationship between 'enlightenment' and 'experience'}

Internationally, among planetarium dissemination professionals, there are two main perspectives. One perspective is that planetarium dome programmes can be focused on the visitors' enlightenment OR their experience, but that programmes cannot focus on both at the same time. This means that programmes that are enlightening cannot be experiential at the same time, and vice versa.

The other perspective is that enlightenment and experience CAN and DO go hand in hand in planetarium dissemination. This means that a programme that is experiential is also enlightening, and vice versa.

Which idea do you agree the most with?

$\square \quad$ Dome programmes can focus on the visitor's enlightenment OR their experience, but not both at the same time.

$\square \quad$ Dome programmes can focus on the visitor's enlightenment and their experience at the same time. A programme that is enlightening is also experiential, and vice versa.

$\square \quad$ Other [Long answer textbox]

Please give an example from a dome programme at your planetarium that illustrates the relationship between enlightenment and experience that you indicated above. Please describe in detail how the relationship between enlightenment and experience is manifested in the example.

[Long answer textbox]

If you have questions or comments about this survey, please type them below.

[Long answer textbox]

Thank you very much. If we may contact you for follow-up questions, please type your e-mail address in the box.

[Short answer textbox] 